\title{
UNIFICA JURISPRUDENCIA EN EL SENTIDO QUE "LOS PERMISOS SINDICALES, EN TANTO SE PRETENDAN REGULADOS DE MANERA DISTINTA -SUPERIOR-A LA ESTABLECIDA POR LA LEY, DEBEN CORRESPONDER, O SER PRODUCTO DE UNA NEGOCIACIÓN QUE CONSTE POR ESCRITO” (EXCMA. CORTE SUPREMA, ROL No 4.187-2013, DE 14 DE OCTUBRE DE 2013).
}

\author{
EDUARDO YÁÑEZ MONJE* \\ Universidad de Chile
}

El fallo que comento a continuación es interesante no tanto por su resultado, el que era de una u otra forma inevitable, sino más bien por su razonamiento. Admito que el problema es oscuro y no es fácil acercarse a él, aun así me atreveré a discrepar de la Excma. Corte Suprema, siempre con altura de miras y con un ánimo estrictamente académico. Nuestro máximo Tribunal, en la causa Rol no 4.187-2013, de 14 de octubre de 2013, caratulado "Inspección Comunal del Trabajo de Providencia con Tresmontes Lucchetti S.A." ha señalado que: "los permisos sindicales, en tanto se pretendan regulados de manera distinta -superior- a la establecida por la ley, deben corresponder, o ser producto de una negociación que conste por escrito".

Sin más preámbulo que el anterior paso directamente a los hechos; la Inspección del Trabajo interpone denuncia por prácticas antisindicales en contra de la empresa ya referida en la carátula de la causa, consistente en el descuento de la remuneración de los permisos sindicales utilizados por la dirigente sindical -durante varios meses- en forma superior a aquellos establecidos en el instrumento colectivo de trabajo. Específicamente, los permisos sindicales, según el instrumento colectivo del trabajo, eran pagados por el empleador pero con un tope de 24 horas de permiso sindical al mes, sin embargo, durante una cantidad importante de meses, el empleador pagó los permisos sindicales a la dirigente a pesar de que dichas horas excedían en forma considerable el tope de 24 horas establecidas en el instrumento colectivo. Luego, la empresa decidió no pagar el exceso de horas de permisos utilizados, y adicionalmente descontar de la remuneración los permisos pagados en los meses anteriores también en exceso de las 24 horas mensuales. La Inspección del Trabajo argumentó que al haber utilizado durante varios meses los permisos en exceso, y al haber sido pagados por el empleador, dicha práctica ha constituido una regla de conducta en los términos del artículo 1564 del Código Civil, el cual permitiría interpretar que el empleador se encuentra obligado a seguir pagando dichas remuneraciones, y al no haberlo hecho, incurriría en una práctica antisindical de aquellas establecidas en el artículo 289 del Código del Trabajo. Este razonamiento no fue compartido por la Juez de Letras del Trabajo, quien señaló que los hechos referidos "no constituye[n] una regla de conducta aplicable en la especie. Lo anterior, por cuanto las reglas de conducta operan sólo para el caso de los contratos individuales de trabajo

* Ayudante de Derecho del Trabajo y de la Seguridad Social, Facultad de Derecho, Universidad de Chile. 
Eduardo Yañez Monje / Unifica jurisprudencia en el sentido que "los permisos sindicales, en tanto se pretendan regulados de manera distinta -superior- a la establecida por la ley, deben corresponder, o ser producto de una negociación que conste por escrito"

y no para los convenios colectivos, los que conforme al artículo 351 del Código del Trabajo deben constar por escrito"'.

Tanto la Inspección del Trabajo denunciante como la dirigente sindical involucrada (actuando como tercero coadyuvante) interpusieron recurso de nulidad para ante la Corte de Apelaciones respectiva, fundada en la infracción a las normas establecidas en los artículos 249 (sobre permisos sindicales) y 289 (sobre prácticas antisindicales) del Código del Trabajo, señalando que la práctica reiterada de pago de remuneraciones en exceso de los permisos establecidos en el convenio colectivo, constituye un acuerdo tácito entre las partes, y el descuento de dichas remuneraciones pagadas supuestamente en exceso, constituye un práctica antisindical. La Corte de Apelaciones les da la razón a los recurrentes, y anula el fallo del Juzgado de Letras del Trabajo, señalando que; "desde [el] punto de vista de la teoría general de los contratos, la mentada 'regla de conducta' tiene aquí pleno asidero" 2 . Por lo tanto, condena a la empresa a una multa por la práctica antisindical incurrida, al reintegro de las remuneraciones y la publicación del fallo en los registros de la Dirección del Trabajo.

La empresa recurre de unificación de jurisprudencia, valiéndose de diversas sentencias de tribunales superiores de justicia, que dan cabida o niegan el acuerdo tácito en cuanto al pago de permisos sindicales, cuando dicho pago se encontraba regulado por instrumento colectivo. La Corte Suprema, en fallo de fecha 24.10.2013, Rol n 4.187-2013, acoge el recurso de unificación de jurisprudencia, anula la sentencia de la Corte de Apelaciones, y dicta sentencia de reemplazo en los siguientes términos:

“[E]l inciso final del artículo 249 del Código del Trabajo [señala] [...] que "Las normas sobre permiso y pago de remuneraciones, beneficios y cotizaciones previsionales de cargo del empleador podrán ser objeto de negociación de las partes", disposición de cuya literalidad surge la idea de "transacción", "pacto", "acuerdo", que modifique la regulación legal mínima, es decir, que establezca una forma distinta -superior- en cuanto a los permisos y en relación con su pago. Ahora bien, esa variación mejorada de los dos aspectos de que se trata, necesariamente debe constar por escrito, como ya se ha decidido por este Tribunal.

Que la exigencia de escrituración precedentemente concluida deriva tanto de las propias disposiciones que regulan la materia -el resultado de una negociación sea contrato o convenio colectivo, se hace constar en un instrumento que recibe tal denominación-como de su naturaleza, desde que involucra la formación del consentimiento entre sujetos de naturaleza colectiva o entes jurídicos plurales en su composición -parte empleadora, que puede estar conformada por varios de ellos aunados y parte trabajadora, sea como grupo de dependientes o como Sindicato- cuyas voluntades se manifiestan a través de la aquiescencia o disconformidad de sus representantes, de modo que necesariamente debe ser expresa, en tanto envuelve la voluntad de un sinnúmero de personas -afiliados al Sindicato, grupo de trabajadores, integrantes de la empleadora- quienes deben conocer las reglas o condiciones en las que se desenvuelve su relación, a lo que se agrega que sus efectos pueden extenderse a sujetos beneficiados que ni siquiera participaron en su gestación. Por consiguiente, si los

$1^{\circ}$ Juzgado de Letras del Trabajo de Santiago; S-57-2012; de 13.11.2012, caratulado "Inspección Comunal del Trabajo de Providencia con Tresmontes Lucchetti S.A."; (Considerando $8^{\circ}$ ).

Corte de Apelaciones de Santiago; Rol n 1736-2012; de 27 de mayo de 2013; caratulado "Inspección Comunal del Trabajo de Providencia con Tresmontes Lucchetti S.A.” (Considerando $7^{\circ}$ sentencia de nulidad). 
pactos colectivos deben constar por escrito, las alteraciones a dichos pactos deben hacerse constar de la misma manera. Dable es recordar que "en derecho las cosas se deshacen de la misma manera como se hacen", de lo que se deriva la necesidad de modificar o enmendar de igual modo". (Considerando $5^{\circ}$ y $6^{\circ}$ de la sentencia de reemplazo de la Excma. Corte Suprema).

Antes de pasar al análisis de estos considerandos, me parece importante citar el artículo 249 del Código del Trabajo de una forma más extensa, pues la cita que hace la Corte Suprema es parcial. Dicho articulado sostiene en su inciso cuarto que: "El tiempo que abarquen los permisos otorgados a directores o delegados para cumplir labores sindicales se entenderá trabajado para todos los efectos, siendo de cargo del sindicato respectivo el pago de las remuneraciones, beneficios y cotizaciones previsionales que puedan corresponder a aquellos durante el tiempo de permiso". Por último en su inciso final señala: "Las normas sobre permiso y pago de remuneraciones, beneficios y cotizaciones previsionales de cargo del empleador podrán ser objeto de negociación de las partes". En consecuencia, de acuerdo al articulado citado, la regla general consiste en que el sindicato debe pagar las remuneraciones y cotizaciones previsionales asociadas por los permisos del dirigentes sindical, sin perjuicio de que, de común acuerdo entre las partes, el empleador asuma dicho gasto. De acuerdo al considerando $5^{\circ}$ recién citado dicho pacto es solemne, esto es, debe contar por escrito, y luego en el inciso $6^{\circ}$ profundiza señalando que la solemnidad se desprende de la "naturaleza" del pacto, pues "involucra la formación del consentimiento entre sujetos de naturaleza colectiva o entes jurídicos plurales en su composición”. Ahora bien, el considerando $5^{\circ}$ no establece distinciones en cuanto a la exigencia de solemnidad, siendo aplicable tanto a una modificación expresa del convenio colectivo como a un pacto individual entre dirigente y empleador, pero el inciso sexto, al explicar la exigencia de dicha solemnidad, establece que se deriva del consentimiento de "sujetos de naturaleza colectiva", por lo tanto, es posible suponer que la Excma. Corte Suprema, se está refiriendo en todo momento a la modificación del convenio colectivo en cuanto tal.

Que un convenio colectivo no puede ser modificado en forma consensual (expresa o tácita) es bastante evidente, efectivamente la legislación exige su escrituración, y esa circunstancia -de acuerdo a las reglas generales sobre formación del consentimiento- impide que se puedan efectuar modificaciones por la vía consensual. Pero eso nada dice acerca de los pactos individuales entre un trabajador afecto a un convenio colectivo y su empleador, en que la legislación no exige solemnidad y las variaciones -en relación a lo que dice el convenio colectivo- pueden producirse en forma tácita.

Al parecer esta circunstancia no fue explicitada en ninguno de los fallos sobre esta causa; de hecho el Juzgado de Letras del Trabajo al momento de exponer el contenido de la denuncia por prácticas antisindicales, señala que de acuerdo al denunciante, existe "una conducta uniforme y permanente en el tiempo, lo que da cuenta de un acuerdo tácito entre la empresa y el sindicato" ${ }^{\text {. }}$ Por lo tanto, la manera de plantear la denuncia fue inadecuada, pues supone que se pueden modificar tácitamente las condiciones entre la empresa y un sindicato, reguladas en un instrumento colectivo, lo que es implausible de acuerdo a lo que señalamos en el párrafo anterior. Luego, la Corte de Apelaciones señaló en su considerando $7^{\circ}$ que:

Considerando $1^{\circ}$ sentencia $1^{\circ}$ Juzgado de Letras del Trabajo de Santiago; S-57-2012; de 13.11.2012. 
Eduardo Yañez Monje / Unifica jurisprudencia en el sentido que "los permisos sindicales, en tanto se pretendan regulados de manera distinta -superior- a la establecida por la ley, deben corresponder, o ser producto de una negociación que conste por escrito"

“[d]esde la perspectiva del derecho foral a que pertenece este contencioso, ocurre que el artículo 348 inciso primero del código en permanente referencia estatuye que las estipulaciones de los contratos colectivos reemplazarán en lo pertinente a las contenidas en los contratos individuales de los trabajadores que sean parte de ellos, lo que quiere decir, sin lugar a dudas, que para la parte que lo es del contrato colectivo, las estipulaciones de éste pasan a ser contrato individual".

Esto nos puede ayudar a comprender que los pactos individuales sí pueden ser modificados en forma consensual, pero acto seguido, en el mismo considerando la Corte de Apelaciones dice:

"[s]iendo así, no se advierte de qué manera podría justificarse el discurso que pretende hacer una distinción radical entre la solemnidad del contrato colectivo y la mera consensualidad del individual. Pero hay más, en la especie no se trató de un contrato sino de un convenio colectivo, al que el artículo 351 del código libera de las solemnidades del contrato colectivo, lo que desde luego reafirma el criterio que viene de explicitarse y que es el sustentado por el susodicho artículo 348 inciso primero".

Así, mediante este razonamiento, la Corte de Apelaciones sostiene que puede modificarse por la vía consensual un convenio colectivo, primero porque no es posible efectuar una separación radical entre ambas, (entre el contrato individual y el convenio colectivo) y segundo porque el convenio está liberado de las solemnidades del contrato. Ciertamente este razonamiento pierde de vista que el artículo 351 señala que el convenio colectivo es aquel suscrito sin sujeción a las normas de procedimiento de negociación colectiva reglada, no dice que no deba constar por escrito. Por lo tanto, en este nivel, se sigue discutiendo si se puede modificar tácitamente un convenio colectivo, en circunstancias que la respuesta negativa parece evidente.

Otro razonamiento que merece análisis en la sentencia de la Corte de Apelaciones, es aquella que señala que "desde [el] punto de vista de la teoría general de los contratos, la mentada 'regla de conducta' tiene aquí pleno asidero". La regla de conducta se desprende del artículo 1564 inciso tercero, que establece una regla de común aplicación en materia laboral; "las cláusulas de un contrato se interpretarán... por la aplicación práctica que hayan hecho de ella ambas partes, o una de las partes con aprobación de la otra”. Dicha regla de interpretación ha dado lugar a la teoría de las reglas de conducta, que sirve, como su nombre lo dice, para interpretar de acuerdo a la aplicación práctica que le han dado las partes a una cláusula que pudiere parecer a primera vista ambigua u oscura. De esa manera, y siguiendo a las gratificaciones como modelo, si pacto su pago en un contrato colectivo pero no queda claro si se pagará en forma anual o se darán anticipos, ni tampoco se dice que tipo qué anticipos: si mensuales, trimestrales o de otro tipo; entonces la aplicación práctica que le hayan dado las partes ilustrará cuál ha sido la intención de las mismas. Si en virtud de contrato colectivo el empleador ha otorgado anticipos mensuales de gratificación con aprobación de los trabajadores, debe entenderse que esa es la forma de pago a que alude el contrato. Ahora volviendo a nuestro caso, la Corte de Apelaciones tiene toda la razón al señalar que la regla de conducta "tiene aquí pleno asidero", refiriendo al convenio colectivo, pero eso no significa que se incorporen o modifiquen en forma tácita beneficios establecidos en un instrumento colectivo, pues las reglas de conducta sólo sirven para interpretar cláusulas oscuras, que se esclarecen por medio de la aplicación prácticas que le dan las partes, y en esa calidad, es plenamente aplicable a un contrato solemne, pero nada dice acerca de modificar cláusulas que son claras en su formula- 
ción y aplicación y tampoco sobre incorporar beneficios que no estaban establecidos en el contrato colectivo, porque en ese caso el consentimiento se expresa a través de la solemnidad ${ }^{4}$.

Por lo tanto, habiendo la denuncia sostenido que se modifica tácitamente el acuerdo entre la empresa y el sindicato, y al sostener la Corte de Apelaciones que las reglas de conducta son aplicables a convenios y eso significa que pueden modificarse tácitamente, la Corte Suprema no tuvo más alternativa que analizar el mérito del razonamiento por sí mismo, y rápidamente llegó a la conclusión que el convenio colectivo no puede modificarse tácitamente, pues este requiere de una escrituración, exigencia que se desprende de las normas del Código del Trabajo y de la naturaleza colectiva de las partes involucradas. Sin embargo, como habíamos dicho párrafos atrás, este razonamiento pierde de vista que los trabajadores individualmente considerados sí pueden pactar mejores condiciones con sus empleadores, situación que al no exigirse solemnidad, caben manifestaciones de voluntad tanto expresas como tácitas, lo que no implica en caso alguno modificación del convenio colectivo como tal, sólo la situación específica de ese trabajador. No puede soslayarse esta posibilidad, sobre todo en vista al artículo 311 del Código del Trabajo, que prohíbe la disminución por la vía individual del beneficio colectivo, pues este artículo supone que lo contrario sí es posible (aumento por la vía individual del beneficio colectivo), y a riesgo de ser majadero, si el aumento por la vía individual no es solemne, no existen razones para rechazar una manifestación tácita de voluntad.

Ahora bien, de la lectura del fallo se desprende que el sindicato actualmente contaba con un único socio, esto es, la presidenta por quien se practicó la denuncia, en esas condiciones, difícilmente puede concluirse que han existido prácticas antisindicales, pues no se ve cómo pudieron los descuentos afectar el funcionamiento de un sindicato en los hechos inexistente.

\footnotetext{
$4 \quad$ Esta confusión proviene de la jurisprudencia administrativa de la Dirección del Trabajo; dictamen N N 2511/97 de 25/04/1997; "El pago reiterado de las horas de permiso sindical por parte del empleador unido a la aquiescencia (consentimiento) del sindicato respectivo, constituye un acuerdo de las partes en los términos previstos por el inciso final del artículo 249 del Código del Trabajo, razón por la cual no resulta procedente que el empleador, unilateralmente, suprima el pago de dicho beneficio".
} 